\title{
Política Nacional de Alimentação e Nutrição: celebrando 20 anos de implementação
}

\author{
Elisabetta Recine 1 \\ Luisete Bandeira 2 \\ Tatiane Nunes Pereira 3 \\ Inês Rugani Ribeiro de Castro 4
}

doi: 10.1590/0102-311X00194521

Celebrar os 20 anos da Política Nacional de Alimentação e Nutrição (PNAN) significa celebrar a evolução da agenda de alimentação e nutrição tanto no âmbito do Sistema Único de Saúde (SUS) como nas suas relações com as diferentes áreas de governo e com a sociedade civil.

Se é notável o desenvolvimento conceitual e programático da primeira ${ }^{1}$ para a segunda 2 edição da PNAN, é ainda mais evidente o amadurecimento e a repercussão das diretrizes nos processos organizacionais do SUS, no diálogo interfederativo e intersetorial. Os desafios também foram intensificados nesses últimos anos, quando o campo da alimentação e nutrição se complexificou e se tornou mais disputado. Isso decorre do lugar ocupado pela alimentação no contexto político e econômico e, mais recentemente, ambiental. As disputas têm estas mesmas origens $3,4,5$.

A PNAN, desde sua primeira edição, tem se mostrado uma política pública robusta e essencial. A abordagem da agenda e de seus desafios tem uma coerência interna capaz de lidar com uma realidade que se altera rapidamente. Assim, mesmo que alguns temas tenham ganhado maior visibilidade na atualidade, como sistemas e ambientes alimentares, por exemplo, a abordagem das diferentes diretrizes os acolhe e dá suporte à identificação de necessidades de estudos, formação de profissionais, organização do cuidado, interfaces intersetoriais, entre outras.

Da mesma maneira, tanto na diretriz específica sobre segurança alimentar e nutricional quanto transversalmente nas demais, são identificados temas historicamente presentes em nossa realidade que ganharam contornos dramáticos nos últimos anos, como as desigualdades e as violações dos direitos humanos em geral e à alimentação adequada.

A definição das ações e prioridades da PNAN sempre foi pautada pelo intercâmbio sistemático com centros de pesquisa nacionais e internacionais, seja pela definição dialogada de uma agenda de prioridades de investigação que pudesse preencher lacunas, seja pelo financiamento de pesquisas por meio de editais.

A evolução é nítida, mas ainda há muito que avançar. Essa agenda sempre teve sentido e importância no cotidiano das nossas comunidades, mas nem sempre repercutiu nos ambientes institucionais. Assim, dentre os desafios postos para o avanço da PNAN, destacam-se a qualificação e ampliação da atenção nutricional no SUS (ampliar os resultados dos esforços em relação à atenção primária e aos demais níveis de atenção); a incidência
1 Departamento de Nutrição, Universidade de Brasília, Brasília, Brasil.

2 Organização Pan-Americana da Saúde, Brasilia, Brasil. ${ }^{3}$ Coordenação-Geral de Alimentação e Nutrição, Ministério da Saúde, Brasilia, Brasil. 4 Instituto de Nutrição, Universidade do Estado do Rio de Janeiro, Rio de Janeiro, Brasil. 
nos processos de formação de profissionais de saúde em geral, além de nutricionistas; e a ampliação da articulação intersetorial para que a agenda de alimentação e nutrição seja um tema presente na definição e planejamento de outros setores. Exemplos disso são a ampliação da disponibilidade e do acesso a alimentos saudáveis e o avanço de medidas regulatórias que promovam ambientes alimentares promotores de saúde, aqui entendidos como mediadores entre as cadeias de produção e abastecimento e as escolhas alimentares. Superar o desafio da articulação intersetorial é fundamental para ampliar as oportunidades de planejamento compartilhado de forma que os resultados e impactos potenciais respondam de maneira sistêmica às prioridades da agenda de alimentação e nutrição.

Por tudo isso, é bastante oportuna a iniciativa da Coordenação-Geral de Alimentação e Nutrição do Ministério da Saúde, em parceria com a Organização Pan-Americana da Saúde, de propor e apoiar a realização deste número temático em celebração aos 20 anos da PNAN. Foram considerados os temas abarcados pela PNAN, a interface das autoras e dos autores com áreas de conhecimento ligadas à política e a diversidade regional para a construção deste temático. A edição conta com 18 artigos, sendo um de debate com oito comentários e uma réplica, 12 artigos originais, uma revisão de literatura, um ensaio, um de perspectivas, um sobre questões metodológicas e duas entrevistas. Entre os temas abordados nos artigos estão: a evolução da PNAN nos últimos 20 anos, a PNAN na atenção primária e sua organização para cuidados relacionados à obesidade, a classificação NOVA - que é baseada na extensão e propósito do processamento de alimentos, e sua repercussão em políticas no Brasil e no mundo -, a promoção da alimentação adequada e saudável, a evolução das medidas regulatórias e as estratégias adotadas para proteger o ambiente alimentar, bem como os conflitos de interesses e as atividades político-corporativas na definição de políticas de alimentação e nutrição.

A amplitude da PNAN torna inviável abordar profundamente todas as dimensões que a compõem em um número temático. Temas relacionados às iniquidades em saúde e desigualdades, como a atenção nutricional voltada a povos indígenas, população negra, povos e comunidades tradicionais, igualmente importantes aos incluídos no temático, não foram suficientemente abordados, apesar dos esforços empreendidos para isso. Esses temas, assim como são desafios para a implementação da PNAN, também o são para a pesquisa em alimentação e nutrição.

Acredita-se e espera-se que este temático contribua para a crescente e contínua discussão sobre as políticas e ações - nelas incluídas as de produção do conhecimento - necessárias à prevenção e ao controle de toda forma de má nutrição, o cuidado nutricional, a proteção e a promoção da alimentação adequada e saudável e a plena realização dos direitos à saúde e à alimentação. 


\section{Colaboradores}

E. Recine, L. Bandeira, T. N. Pereira e I. R. R. Castro participaram igualmente na concepção, elaboração e revisão final do manuscrito.

\section{Informações adicionais}

ORCID: Elisabetta Recine (0000-0002-5953-7094); Luisete Bandeira (0000-0001-5520-5167); Tatiane Nunes Pereira (0000-0001-9312-5758); Inês Rugani Ribeiro de Castro (0000-0002-7479-4400).
1. Ministério da Saúde. Portaria no 710, de 10 de junho de 1999. Aprova a Política Nacional de Alimentação e Nutrição. Diário Oficial da União 1999; 15 jun.

2. Departamento de Atenção Básica, Secretaria de Atenção à Saúde, Ministério da Saúde. Política Nacional de Alimentação e Nutrição. Brasília: Ministério da Saúde; 2012.

3. High Level Panel of Experts on Food Security and Nutrition. Nutrition and food systems. A report by the High Level Panel of Experts on Food Security and Nutrition. Rome: High Level Panel of Experts on Food Security and Nutrition, Committee on World Food Security; 2017. (HPLE Report, 12).

4. Rede Brasileira de Pesquisa em Soberania e Segurança Alimentar e Nutricional. VIGISAN: Inquérito Nacional sobre Insegurança Alimentar no Contexto da Pandemia da COVID-19 no Brasil. Brasília: Rede Brasileira de Pesquisa em Soberania e Segurança Alimentar e Nutricional; 2021

5. Swimburn B, Kraak VI, Allender S, Atkins VJ, Baker PI, Bogard JR, et al. The global syndemic of obesity, undernutrition, and climate change: The Lancet Comission Report. Lancet 2019; 393:791-846. 